\title{
GLOBALIZAÇÃO E NOVAS REGIÕES PRODUTIVAS NO NORDESTE BRASILEIRO
}

\author{
Msc. Iara Rafaela Gomes \\ Doutoranda no Programa de Pós-Graduação em Geografia da UFC \\ Grupo de pesquisa Globalização, Agricultura e Urbanização (CNPq) da UECE \\ Av. Paranjana, 1700 - CEP xxxxx-xxx - Fortaleza (CE) - Brasil \\ Tel.: (+ 55 85) 8823.4598 - iara_geo@hotmail.com
}

\begin{abstract}
RESUMO
O principal objetivo desta contribuição é analisar os elementos influenciadores da dinâmica que o agronegócio globalizado, embora não seja o único vetor, vem promovendo para a intensificação da urbanização e do crescimento econômico de cidades locais e médias. Interessa-nos compreender, a partir disso, os novos arranjos territoriais que se organizam no Nordeste brasileiro. Estudamos, em especial, as principais características do processo de urbanização na região que se estende do baixo curso do rio Açu $(\mathrm{RN})$ ao baixo curso do rio Jaguaribe (CE). Desse modo, este estudo analisa e problematiza os processos socioespaciais, resultantes da reestruturação produtiva da agropecuária, colaboradores para o estabelecimento de novas configurações do espaço produtivo, compondo na região supracitada uma região produtiva, associada à fruticultura, sendo, pois, um novo ponto luminoso, no espaço agrário nordestino.
\end{abstract}

Palavras-chaves: Agronegócio, urbanização, região produtiva agrícola, Baixo Jaguaribe, Vale do Açu.

\begin{abstract}
The main objective of this contribution is to analyze the factors that influence the dynamic global agribusiness, although not the only vector, has been promoting more intensive urban development and economic growth of local and medium-sized cities. We are interested in understanding from this the new territorial arrangements that are organized in Northeast of Brazil. We study in particular the main features of the urbanization process in the region that extends from the lower course of the Açu river $(\mathrm{RN})$ to the lower course of the Jaguaribe river (CE). Thus, this study analyzes and discusses the socio-spatial processes resulting from the restructuring of the agricultural production that contributes to the establishment of the new configurations of the production space, making the region above a productive one, associated with fruit, and thus a new light point in the Northeast agrarian space.
\end{abstract}

Key words: Agribusiness, urbanization, productive agricultural region, Baixo Jaguaribe, Vale do Açu.

\section{RESUMEN}

El principal objetivo de este trabajo es analizar los factores que influyen en la dinamica de la agroindustria global, que sin ser el único vector de crecimiento, ha estado promoviendo el desarrollo economico y urbanistico de sus localidades. Estamos interesados en comprender estas nuevas conformaciones territoriales que se organizan en el noreste de brasil. Se estudian en particular las principales características del proceso de urbanización en la región que se extiende desde la parte baja del río Açu (RN) hasta el curso inferior del río Jaguaribe (CE). En este sentido, el presente trabajo analiza y discute los procesos socio-espaciales derivados de la reestructura en la producción agrícola que contribuye a la creación de nuevas configuraciones en el espacio productivo, transformando a la región en una region productiva asociada a la fruticultura, lo que la convierte en un nuevo punto de luz en el espacio agrario en el nordeste.

Palabras-Claves: Agroindustria, urbanización, región agrícola productiva, Baixo Jaguaribe, Vale do Açu.

\section{INTRODUÇÃO}

Na tentativa de compreender os novos arranjos territoriais que se organizam no Nordeste brasileiro a partir das recentes relações entre o processo de urbanização e a expansão da agricultura científica, este trabalho se propõe analisar as principais características deste processo na região que se estende do baixo curso do rio Açu (RN) ao baixo curso do rio Jaguaribe (CE). Esta é uma das áreas, no Brasil, que mais têm interessado aos capitais hegemônicos do agronegócio de frutas tropicais, voltado para a produção intensiva que tem como fim a exportação.

Pensamos a urbanização a partir de análises que buscam ultrapassar o limiar dos parâmetros demográficos que apoiam determinadas classificações. Desse modo, procuramos trabalhar com a compreensão das relações que se desenvolvem entre as cidades e entre estas as áreas rurais, pela identidade ou pela diversidade de seus papéis urbanos. É fundamental destacar que compreende- 
mos o processo de urbanização na perspectiva histórica e as cidades, como formas materiais que expressam o movimento desse longo processo.

Esse estudo possibilitou compreender que o agronegócio globalizado, embora não seja o único vetor, vem desempenhando um papel fundamental para a intensificação da urbanização e para o crescimento econômico de cidades locais e médias. Destacamos que os impactos socioespaciais resultantes da reestruturação produtiva da agropecuária vêm se dando de forma acentuada, seja no campo, seja na cidade, estabelecendo-se novas configurações do espaço produtivo, compondo na região localizada entre o baixo curso do rio Jaguaribe (CE) e o baixo curso do rio Açu (RN), uma região produtiva, associada à fruticultura, sendo, assim, um novo ponto luminoso no espaço agrário nordestino.

Esse artigo está dividido em duas grandes partes que se subdividem entre si. Na primeira, apresentaremos os principais pressupostos teóricos e os elementos da análise utilizados na compreensão das transformações ocorridas no espaço geográfico brasileiro, destacando, sobretudo, as importantes metamorfoses verificadas com o processo de modernização da agricultura, sob a lógica do agronegócio globalizado que, consequentemente, promove, em paralelo ao seu desenvolvimento, a expansão das áreas urbanizadas e a intensificação das relações campo-cidade. Ainda nesta parte, apresentaremos brevemente uma ponte entre o processo mencionado que ocorre no Brasil e seu desdobramento no cenário nordestino. Na segunda parte, mostraremos a região de estudo, um pouco de sua história e de suas principais características, sobretudo a relação entre sua produção agrícola e, as dinâmicas da economia urbana, e ainda sua dinâmica populacional e mercado de trabalho. Por fim, teceremos algumas considerações finais sobre as discussões realizadas na pesquisa e seus resultados.

\section{Agricultura e Urbanização no Brasil}

O processo de transformação do Brasil essencialmente agrário para uma das principais economias mundiais deve-se à expansão da globalização da economia e à tentativa de se inserir o país no mercado mundial. Isso vem promovendo intensas modificações políticas, econômicas e territoriais. Os impactos resultantes dessas transformações são significativos, principalmente com o incremento da divisão social e territorial do trabalho, promovida pela dispersão espacial da produção e relocação de todos os fatores econômicos, que reorganizaram os investimentos produtivos no país.

A partir da década de 1960, as políticas públicas foram fundamentais para o desdobramento dessa organização espacial. Nele foram criadas renomadas instituições, tais como o Banco Nacional de Habitação (BNH), a Comissão Nacional de Regiões Metropolitanas e Política Urbana (CPNU), o Programa de Ação Concentrada (PAC) e o Plano Nacional de Desenvolvimento (PND), os quais surgem como resultado da busca do crescimento econômico incrementada pelo governo federal. Este governo atuou de forma incisiva no processo de interiorização e de acumulação de capital reorganizando os investimentos produtivos no país. Quanto às políticas no meio rural, citamos o Estatuto da Terra, editado em 1964, cujo objetivo principal era modernizar a agricultura no país em áreas selecionadas. Esse Estatuto, assim como o do Trabalhador Rural, criado em 1963, veio coadunar-se com as ânsias e necessidades de expansão do capitalismo industrial e financeiro.

Indiscutivelmente, a globalização da economia promoveu grandes transformações no processo produtivo, vinculado à agropecuária existente no atual período, que corresponde a um setor que se relaciona, de forma cada vez mais acentuada, com os demais setores da economia. Esta, assim como aqueles setores, não funciona mais isoladamente. Graziano da Silva (1998), ao trabalhar o recente desenvolvimento da agricultura, faz referência ao conceito de integração de capitais.

Sobre as novas relações que se formam entre a agropecuária e os demais setores econômicos, Elias (2002a) nos fala dos circuitos espaciais da produção e dos círculos de cooperação, os quais mostram que essas relações extrapolam os limites dos estabelecimentos agrícolas, de uma região ou país, associando, sobretudo, a atividade agropecuária ao circuito superior da economia (SANTOS, 
1988, 1994, 2004). Desde então, a lógica agrícola obedece aos desígnios da acumulação industrial, a partir do desenvolvimento dos complexos agroindustriais (CAIs) (GRAZIANO DA SILVA, 1998). Surge profundo interesse em produzir commodities e matérias-primas para as agroindústrias, assim como a produção da agricultura passa a exigir uma grande busca dos produtos já industrializados.

A partir dos anos 2000, a produção agrícola tem sua dinâmica cada vez mais organizada pela economia de mercado e, sob essa lógica, haveria a ascensão das relações estabelecidas por meio das trocas financeiras, realizadas pelo comércio, que, consequentemente, ocorrem com base nas demandas industriais. Os setores da economia imbricam-se de forma crescente, sobretudo a partir das substituições da produção de subsistência pela de mercado e dos insumos naturais pelos industriais. Um exemplo disso são os dados do Instituto Brasileiro de Geografia e Estatística (IBGE), via Censo Agropecuário (1970) e Produção Agrícola Municipal (2000), segundo os quais a laranja e a soja incluem-se entre os principais produtos agrícolas de exportação do Brasil, com crescimentos consideráveis nas quantidades produzidas para o período de 1970 a 2000. Se compararmos o crescimento da produção brasileira das culturas tradicionais de subsistência como o milho, o feijão e a mandioca, constataremos que houve crescimentos pouco representativos no mesmo período . Quanto à substituição dos insumos, podemos apontar, também, os dados do Censo Agropecuário do IBGE (1995), que destacam, para este ano, um percentual de mais de $90 \%$ dos estabelecimentos rurais do país utilizando agrotóxicos, adubos químicos e outros insumos.

Como mostram os dados, a reestruturação produtiva da agropecuária, processo complexo de transformações de todos os aspectos associados à essa produção da agropecuária, tem-se apresentado como um dos principais vetores da reorganização do território brasileiro. É esta reestruturação em curso nos últimos anos que promove o incremento do capitalismo no campo a partir do mencionado agronegócio globalizado.

Conforme defende Elias (2003, 2006a; 2006b; 2006c; 2006d), a expansão do agronegócio globalizado ocorre paralelamente à fragmentação do espaço agrícola. Para a autora, esta nova dinâmica sugere intensa mecanização desses espaços agrícolas com o incremento de uma nova materialidade e de ações consoantes, que têm permitido novos usos para o território, expandindo, ainda, a substituição dos meios natural e técnico pelo meio técnico-científico-informacional (SANTOS, 1985, 1988, 1993, 2004), onde o território passa a ser reorganizado e a expansão do seu processo de urbanização passa a responder efetivamente a este novo modelo. Desse modo, a nosso ver, a reestruturação produtiva da agropecuária é um ponto fundamental para compreender a urbanização brasileira contemporânea.

\section{O Nordeste brasileiro e a modernização da agricultura}

A década de 1960 é um marco para o planejamento regional no Brasil e, particularmente, para a região Nordeste. Nesse período, coordenado por Celso Furtado, é produzido o Relatório do Grupo de Trabalho para o Desenvolvimento do Nordeste (GTDN) na busca do desenvolvimento regional, culminando na criação da Superintendência do Desenvolvimento do Nordeste (SUDENE) e fundamentando a estratégia inicial desta. A partir da década de 1970, não seriam mais os Planos de Desenvolvimento que passariam a direcionar o planejamento regional, pois nesse período surgem os Planos de Desenvolvimento do Nordeste, inseridos, obviamente, nas diretrizes do Planejamento Nacional, frutos dos Planos Nacionais de Desenvolvimento (PNDs).

A década seguinte, a de 1980, foi marcada, sobretudo, pelo agravamento das crises econômicas, fiscal e financeira do Estado e caracteriza-se por um período de intensa recessão. Neste momento identificam-se constantes dificuldades da economia brasileira para retomar seu crescimento e a intensificação da abertura, com seus impactos diferenciados sobre o espaço regional. No Nordeste, com a crise, embora o Estado tentasse cortar gastos no setor agrícola, também buscou proporcionar investimentos para as culturas de exportação, no intuito de alavancar a balança comercial e prover

Mercator - volume 9, número 20, 2010: set./dez. 
recursos para pagamento da dívida . Neste momento, a irrigação privada passa a ser o novo gargalo do Estado, orientada agora exclusivamente para o mercado. Surgem o Programa Nacional de Aproveitamento Racional de Várzeas Irrigáveis (PROVÁRZEAS) e o Programa de Financiamento para Equipamentos de Irrigação (PROFIR).

Ainda nesta década, ocorre a queda do cultivo do algodão nos perímetros irrigados. Registramos para o Nordeste quedas de produção e área colhida entre 1985 e 1996 (Censo Agropecuário - IBGE). A produção em 1985 foi de 399.791 toneladas em uma área colhida de 960.730 hectares e para o ano de 1996 tivemos uma produção de 76.225 toneladas em uma área colhida de 162.436 hectares . Esta cultura veio diminuindo ao longo do tempo, tanto pela praga do bicudo quanto pela ausência de estímulos econômicos. Tal situação acabou por fomentar o incentivo ao cultivo de novas culturas. Surge, então, a fruticultura tropical como ponta de lança promissora para o sucesso dos perímetros e solução para o semiárido nordestino. Muitas características evidenciavam esta região como promissora nesta nova empreitada, tais como as naturais - altas temperaturas, baixa umidade relativa do ar, luminosidade acentuada etc. -, as econômicas - como o baixo preço das terras agricultáveis - e as tecnológicas - com o investimento em novas tecnologias (ELIAS, 2002a).

A partir de 1980, a agropecuária do Nordeste, até, então, sem grandes alterações, passa a ver o surgimento da ocupação de novas áreas pelo agronegócio globalizado. Essas são parte do exército de lugares de reserva para o agronegócio que foi incorporado recentemente aos circuitos produtivos globalizados de empresas nacionais e multinacionais hegemônicas do setor, assumindo um novo papel na divisão internacional do trabalho agrícola (ELIAS, 2006b). As relações tipicamente capitalistas vêm afetando os espaços agrícolas do Nordeste e transformando sua agricultura de forma seletiva, atingindo determinados lugares e especializando suas culturas. Nesse período, o oeste da Bahia foi a primeira área do Nordeste a vivenciar essa difusão do agronegócio e a difundir a produção intensiva de soja, assim como o submédio do rio São Francisco foi o primeiro a difundir a produção de frutas para exportação.

Em meados da década de 1980, a produção intensiva de frutas tropicais passou a ocupar o baixo curso do rio Açu, no Rio Grande do Norte, e, a partir de 1990, essa mesma produção ocupa o baixo curso do rio Jaguaribe, no Ceará. Esta área formada por municípios do Ceará e do Rio Grande do Norte compõe uma região produtiva, associada à fruticultura e é um dos espaços agrícolas recentemente incorporados à produção intensiva.

A região em análise está localizada entre o nordeste cearense, região do baixo curso do rio Jaguaribe e o noroeste potiguar, Mossoró, e baixo curso do rio Açu. Esta, segundo Elias (2006b), é uma das regiões que mais tem interessado aos capitais hegemônicos do agronegócio no Nordeste, voltada para a produção intensiva de frutas tropicais para exportação. É, também, uma das que passaram a participar dos circuitos espaciais da produção (SANTOS, 1988) globalizada muito recentemente.

Esta região guarda características privilegiadas no que se refere aos seus aspectos naturais. No Baixo Jaguaribe $(\mathrm{CE})$ temos um vale úmido próximo à Chapada do Apodi, com uma rede hidrográfica de grande importância para a região jaguaribana. Já a porção nordeste da bacia do Piranhas-Açu (RN), correspondente a uma planície aluvial, é também um dos espaços privilegiados no semiárido do Rio Grande do Norte. Embora seus municípios pertençam à Zona Semiárida do Nordeste, marcada particularmente por sua sensibilidade às secas periódicas e pela presença de solos pouco agricultáveis, a área definida como "Baixo Açu” é classificada como "mancha fértil”" (SILVA, 1992).

\section{UMA NOVA REGIÃO PRODUTIVA AGRÍCOLA NO NORDESTE BRASILEIRO}

Para apresentar esta região produtiva agrícola, é necessário retomarmos a questão da reestruturação produtiva da agropecuária, pois esta guarda uma característica fundamental para a formação da região, qual seja, sua essência seletiva que manteve intocáveis algumas estruturas sociais, territoriais e políticas enquanto outras se tornaram verdadeiros enclaves de modernização. Assim, 
foram privilegiados determinados segmentos sociais, econômicos, bem como os espaços que puderam responder mais rapidamente à lógica capitalista.

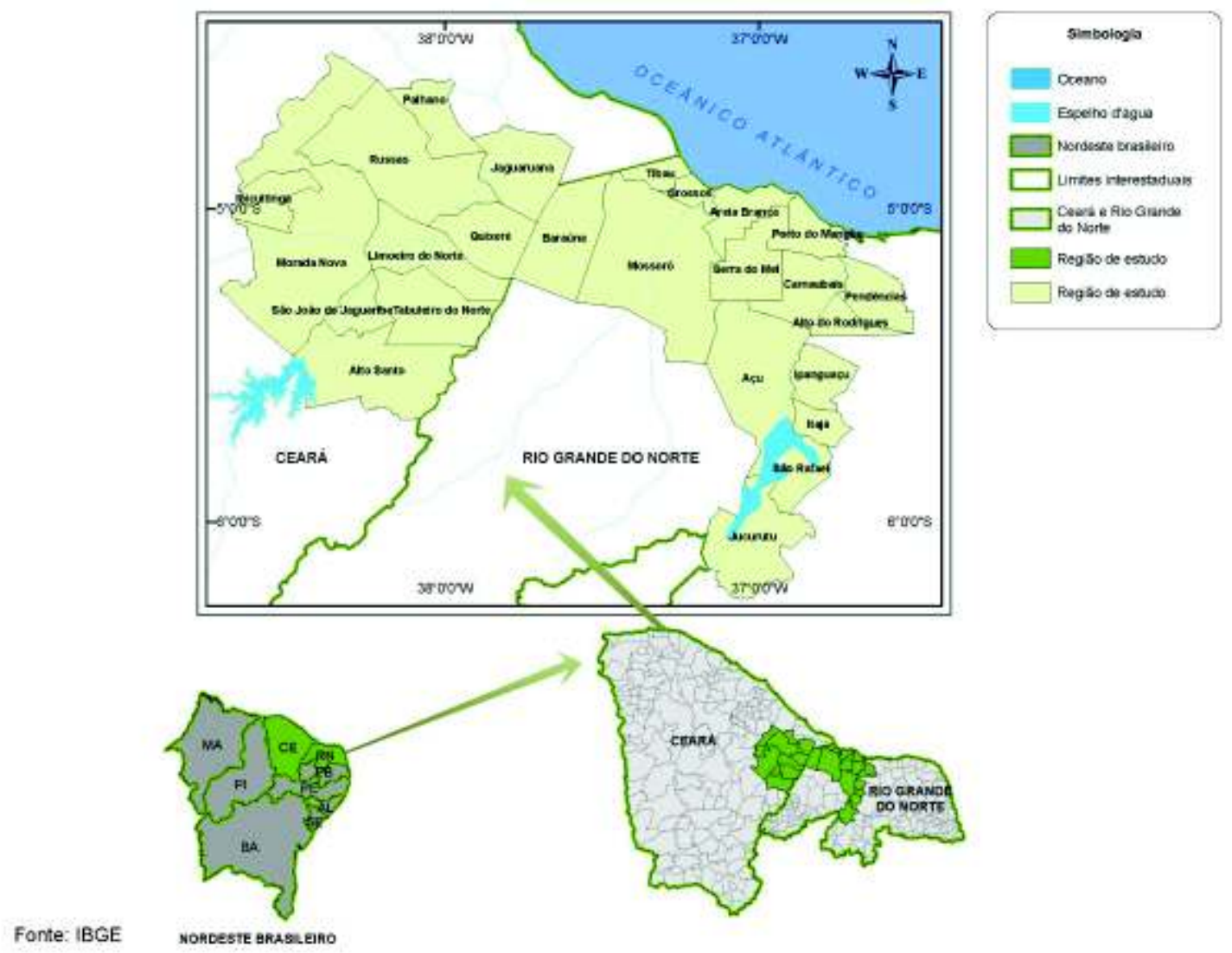

Figura 1 - Localização da região produtiva agrícola

Desse modo, como consequência da territorialização do capital no campo, há um incremento da oligopolização do espaço agrícola brasileiro, acompanhado de um paralelo processo de fragmentação deste, culminando numa nova divisão territorial do trabalho diretamente relacionada ao setor agrícola. Como podemos observar, as políticas públicas são direcionadas a partir deste novo modelo para certos espaços e os dotam de um novo conjunto de objetos e de ações que os diferencia de outros espaços, promovendo, efetivamente, a constituição de verdadeiras regiões produtivas (SANTOS, 1985).

Trabalhamos com a hipótese de que entre o baixo curso do rio Açu, no Rio Grande do Norte, e o baixo curso do rio Jaguaribe, no Ceará, existe uma região produtiva agrícola. Para chegarmos à formação desta região, além dos critérios iniciais utilizados para definir este recorte espacial, quais sejam, as microrregiões do IBGE; as características naturais geográficas; a presença de ações efetuadas com vistas ao agronegócio e os respectivos agentes produtores do espaço, traçamos-lhe um perfil sob outros aspectos com o objetivo de inserir em seu conjunto cada município que a consolidaria:

1. A influência da expansão agrícola sobre a região e, portanto, sobre cada município;

2. A importância do agronegócio da fruticultura na consolidação da região como polo de destaque no conjunto regional nordestino e nacional;

3. A existência de circuitos produtivos e círculos de cooperação consolidando a região produtiva por meio do agronegócio da fruticultura;

4. A partir do desenvolvimento do agronegócio nessa região, consideramos a significação de cada município na produção das principais culturas para exportação, assim como os municípios que sobressaem no direcionamento de políticas públicas voltadas para o setor agrícola 
e aqueles em evidência na inserção de sistemas de objetos, desse modo, de um conjunto de objetos técnicos em seus espaços.

Do ponto de vista espacial, um dos principais impactos da difusão de elementos do meio técnico-científico-informacional (SANTOS, 1993) foi sua capacidade de articular espaços, promovendo e incrementando as interações entre lugares, por vezes muito distantes entre si. Como o meio técnico-científico-informacional constitui o entorno do homem moderno, cercando-o cada vez mais com novos objetos técnicos que medeiam suas ações, a penetração e as manifestações desses elementos no espaço social construído são inumeráveis e se renovam continuamente.

Dessa forma, algumas variáveis foram selecionadas para indicar tanto a expansão agrícola e a influência da modernização deste setor nas transformações mais recentes, que concorrem para reforçar o destaque e a existência da região produtiva agrícola, quanto a presença de infraestruturas e o crescimento de objetos técnicos. Ou seja, elementos do meio técnico-científico-informacional que podem veicular a formação e organização desta região produtiva agrícola, colaborando para mostrar seus diversos níveis de organização espacial e, consequentemente, a importância de todas essas variáveis para a compreensão do processo de urbanização estabelecido na região em estudo. Foram elas:

. Área plantada e quantidades produzidas das culturas de exportação. Estas, entre outros processos, refletiram a metamorfose na pauta produtiva da região que, por sua vez, pôde evidenciar a inserção no agronegócio globalizado;

. Estabelecimentos do comércio. Tais estabelecimentos, principalmente ligados ao consumo produtivo, nos motivaram a compreender o dinamismo da economia urbana associada à modernização agrícola;

. População Economicamente Ativa urbana e rural. Essa variável revelou a concentração econômica, sobretudo como o incremento da PEA urbana pode refletir a dinâmica da economia urbana das cidades da região;

. Terminais telefônicos em serviço. Por referidos terminais pudemos observar a circulação de informações, inclusive por redes de computadores;

. Emissoras de rádio e provedores da Internet. Essas emissoras e esses provedores refletem um incremento do consumo de energia (megawatts) que já é um reflexo da difusão de objetos técnicos do meio técnico-científico-informacional, pois a modernização das atividades econômicas, especialmente aquelas em meio urbano, demanda energia elétrica para seu funcionamento. Refletem também, e sobretudo, a difusão da informação que mostra como vem se dando uma maior integração com lugares cada vez mais distantes entre si;

. Terminais rodoviários em serviço. Tais terminais indicam a demanda por transporte de pessoas (e também de mercadorias) via sistema rodoviário;

. Análise da população residente. Essa variável mostrou o dinamismo da demografia na região em estudo que, paralelamente a uma revolução tecnológica da produção agropecuária e agroindustrial e às transformações nas relações de trabalho, desenvolveu uma dinâmica demográfica e urbana, marcada por grande crescimento populacional, particularmente urbano;

. Número de empregos formais nos setores da economia. Por este dado, pudemos evidenciar o dinamismo da economia, com a difusão de determinados segmentos econômicos, em que um exemplo foi a ocupação formal na agricultura como um bom indicador da difusão do agronegócio; 
. Existência de subcontratação nas relações de trabalho. Com base em tal informação, pudemos perceber a reestruturação nas relações de trabalho atuais;

. Evolução do emprego qualificado. Como fruto de maior exigência das empresas para a realização de atividades que requerem maior nível de especialização, esta evolução pôde sugerir, por exemplo, a formação de mercados de trabalho com características dominantemente capitalistas, como é o caso da atividade agropecuária.

Todos esses dados foram analisados e apenas alguns são mencionados no corpo deste trabalho, tanto como comprovação empírica da pesquisa como também para que nossas afirmações neste momento não resultem vazias de verdade.

Quanto à articulação da região produtiva agrícola em estudo, esta se dá em diversos níveis de organização espacial, a saber: nível internacional, no caso do mercado mundial de frutas; nível nacional, pela absorção de fluxos migratórios e aquisição de bens de consumo industrializados de outras regiões; nível regional, mediando e enviando fluxos que atravessam a região para alguns portos (Suape, Natal, Pecém) e daí para outros lugares; nível sub-regional, nas interações espaciais entre as cidades da própria região.

A partir da análise das variáveis ora citadas, denominamos como uma região produtiva agrícola o território formado por 25 municípios situados entre o nordeste cearense (região do baixo curso do rio Jaguaribe) e o noroeste potiguar (Mossoró e baixo curso do rio Açu). Esses municípios estão inseridos em três microrregiões geográficas do Instituto Brasileiro de Geografia e Estatística, quais sejam: Baixo Jaguaribe (CE), Mossoró (RN) e Vale do Açu (RN).

Conforme Santos (1985, p. 72), “o território é formado por frações funcionais diversas". No nosso entendimento, uma região produtiva pode ser uma dessas frações. Para este autor, sua definição "exige o reconhecimento das suas relações internas e externas mais importantes [...]" em uma tentativa de captar sua especificidade, hoje e em períodos anteriores, dada pela forma como as condições presentes são utilizadas (em função de forças internas a vários níveis e de forças externas a diversas escalas) (Santos, 1985, p. 72).

$\mathrm{O}$ espaço brasileiro sugere seu entendimento segundo diferentes lógicas de organização. Isso é fato também na organização dos seus espaços agrícolas. Desse modo, podemos citar uma que é modernizadora e que articula a escala local com a internacional, com base nas novas dinâmicas hegemônicas do agronegócio globalizado. Para Elias (2005, 2006a; 2006b; 2006c; 2006d), a fragmentação do espaço agrícola denota a constituição de arranjos territoriais produtivos agrícolas. Estes, segundo a autora (2006b, p.10) "são as regiões produtivas agrícolas dinâmicas".

Soja (1993) fala da especialização flexível, em que os sistemas de produção verticalmente desintegrados e o rompimento das hierarquias rígidas têm sido acompanhados por uma mobilidade acelerada do capital, para facilitar a busca de superlucros setoriais em qualquer parte do mundo. A região produtiva localizada entre o baixo curso do rio Açu $(\mathrm{RN})$ e o baixo curso do rio Jaguaribe (CE) ilustra esse tipo de especialização e foi absorvida pelo capital, pois, entre outros elementos, o "superlucro" de algumas multinacionais frutícolas é obtido mediante barateamento substancial dos custos com mão de obra encontrada em abundância nessa região. Observamos mais especificamente o caso da multinacional Del Monte Fresh Produce Ltda., uma das três principais empresas do setor de frutas do mundo que, em poucos anos, promoveu grandes transformações na produção, difundindo a agricultura científica e o agronegócio de frutas tropicais. Instalada no Vale do Açu, esta empresa produz, sobretudo, banana, especialmente no município de Ipanguaçu. Já no Vale do Jaguaribe destaca-se com a produção de melão, o município de Quixeré, e de abacaxi, o município de Limoeiro do Norte. Portanto, via terra e mão de obra, são estabelecidas as principais relações com o lugar, pois esta empresa traz de outros países todo o seu pacote tecnológico e serviços especializados e exporta quase toda a sua produção (ELIAS, 2006b). 
O Baixo Açu, no Rio Grande do Norte, de longa data se caracterizou como uma região cuja atividade principal é, sobretudo, relacionada com o setor agrícola, predominando o complexo algodão-pecuária-lavouras alimentares, associado à extração de cera de carnaúba (VALVERDE, 1961). No Baixo Jaguaribe (CE), seu processo de territorialização também destaca a agropecuária e o extrativismo vegetal como alicerces para seu processo de urbanização. Segundo Valverde, "é sempre útil comparar os baixos vales do Açu e do Jaguaribe, já que as condições naturais são semelhantes, assim como as atividades econômicas, o habitat e a elevada densidade de população" (1961, p. 483).

Dentre as adversidades ambientais, o clima na região em análise é dominantemente semiárido. Esse clima produz taxas elevadas de evapotranspiração que dão ensejo a um balanço hídrico fortemente deficitário na maior parte do ano. De modo geral, os solos da região são bem diversificados, e, como foi mostrado por determinados estudos, partes consideráveis têm sido degradadas, comprometendo, inclusive, sua capacidade produtiva. Entretanto, a área concentra solos potencialmente férteis, nos quais, como supracitado, existem "manchas férteis" em alguns espaços, como é o caso, por exemplo, dos cambissolos da Chapada do Apodi, dos podzólicos dos tabuleiros arenoargilosos e das aluviões das planícies fluviais (SOUZA; OLIVEIRA; GRANJEIRO, 2003).

A junção desses aspectos materializa-se em condições naturais favoráveis à fruticultura que, aliadas aos aspectos infraestruturais e econômicos, como a construção dos reservatórios de recursos hídricos, o uso da irrigação, a melhoria nos sistemas viários entre outros, tornam-se fatores de atração de empresas agrícolas modernas e mercado de insumos, favorecendo o estabelecimento das cadeias de produção de frutas.

$\mathrm{Na}$ verdade, em decorrência do potencial da fruticultura, a região passou a ser apontada como essencial e sustentáculo da economia regional nordestina proposta pelas novas estratégias do governo federal, ou seja, um eixo privilegiado para que os grandes investimentos a tornem um centro competitivo integrado aos mercados nacional e internacional. Neste sentido, não somente a produção agrícola da região é modificada, mas também sua economia urbana, sua dinâmica populacional e o seu mercado de trabalho, que passam a responder de forma bastante diferenciada dos períodos precedentes

\section{CARACTERÍSTICAS DA PRODUÇÃO AGRÍCOLA E DA ECONOMIA URBANA}

A década de 1970 é marcada por grandes transformações decorrentes do período técnico-científico-informacional. Segundo Elias (2003), no Brasil, neste período, os fenômenos da terciarização e da urbanização ocorrem em uníssono e se distinguem, sobretudo, nas áreas mais receptivas ao processo de modernização da economia e do território, culminando com a expansão do meio técnico-científico-informacional (SANTOS, 1985, 1988, 1993, 2004). Como aponta a autora ao utilizar os trabalhos de Milton Santos (1979), o estudo do setor terciário a partir da urbanização e das condições atuais da economia internacional sugere levar-se em consideração a imensa quantidade de atividades econômicas que surgem e que fogem à atual classificação, causando, inclusive, preocupação aos analistas e aos pesquisadores ante o risco de subordiná-las simplesmente aos dados e, assim, cometerem graves erros caso as novas atividades não sejam incluídas em um quadro atualizado e menos restrito à classificação simplista da atualidade.

No Brasil, podemos citar como exemplo de um dos lugares a responder intensamente à lógica da produção agrícola globalizada, e que fez surgir muitas atividades alheias às classificações atuais e tradicionais das atividades econômicas, a região produtiva agrícola que se estende do baixo curso do rio $A c ̧ u(R N)$ ao baixo curso do rio Jaguaribe (CE). Para podermos compreender a urbanização dessa região, é fundamental conhecer essas novas atividades, sobretudo aquelas associadas ao "terciário". Entretanto, não podemos contar exclusivamente com uma análise mais detalhada dessas atividades com base nos dados estatísticos porque tais dados muitas vezes inexistem. 
Conforme afirma Elias (2003), quanto à produção agropecuária moderna, sua globalização ocorre com a inserção da ciência e da tecnologia na produção, na distribuição e no transporte que passam a utilizar novos produtos e serviços, demandando consequentemente maior especialização. Desse modo, o desenvolvimento das atividades agropecuárias relacionadas à agroindústria integra-se de forma cada vez mais crescente ao circuito superior da economia urbana. Incrementa-se a urbanização com essa integração acelerada entre as atividades agropecuárias e a economia urbana, e surge então também um novo tipo de consumo, ou seja, aquele associado à produção, o que é denominado por Milton Santos (1993) de consumo produtivo . Na região produtiva em análise, este consumo tem revelado uma das faces do incremento das relações campo-cidade.

Para compreender a modernização agropecuária e sua relação com a economia urbana, é importante destacar as políticas governamentais e seu importante papel neste processo. Com vistas a superar as dificuldades impostas pelas condições físicas do semiárido no Nordeste brasileiro, a ênfase das políticas governamentais para a agricultura consistiu no incentivo da irrigação para as áreas semiáridas da região. Nela, os projetos de irrigação foram implantados em áreas que dispõem de melhor dotação de recursos de água e de solo. Nos anos 1970, as áreas de influência dos projetos públicos de irrigação foram caracterizadas como polos de atração para as populações que migraram do campo para as cidades e, mais ainda, os investimentos públicos e privados na irrigação criaram economias externas e efeito multiplicadores no Nordeste. Estes permitiram a localização de inúmeras agroindústrias processadoras de matérias-primas locais (CARVALHO, 1997).

Desse modo, a produção de frutas tropicais tem sido alvo da atenção do poder público, explicitada, sobretudo, pelo favorecimento e pela transferência considerável de incentivos financeiros. $\mathrm{O}$ apoio do Estado foi demonstrado pelo financiamento de infraestrutura de irrigação, como as perfurações de poços artesianos de maior profundidade (variando de 700 a 1.000 metros), assim como a construção de grandes obras como a barragem Armando Ribeiro Gonçalves (SILVA, 1999).

Com a implantação dos projetos privados de irrigação, desde a segunda metade da década de 1980, em vários municípios da região em análise, acirrou-se o mercado de terras. Assim, a modernização da agricultura que se processa nesta região deu-se com a exclusão dos pequenos produtores e dos trabalhadores sem-terra. A partir da década de 1990, já submetida aos moldes de uma agricultura científica e do agronegócio globalizado e devido à influência dos fatores naturais, histórico-sociais e econômicos, os elementos do espaço agrário da região produtiva em análise apresentam diversas variações. Nesta, o aproveitamento da terra tem sido cada vez mais intensivo, e as áreas que a compõem estão cada vez mais integradas em comparação com os demais espaços agrários do Nordeste.

A partir da divisão espacial das atividades e do papel dos fatores históricos e naturais, podemos refletir sobre o uso da terra na região em estudo. Apesar de algumas características comuns consolidarem esta região produtiva agrícola, seu espaço não é homogêneo e constitui-se de diferentes áreas. Entre outras, área de culturas diversificadas e de subsistência, e área de agricultura comercial especializada (fruticultura) são aquelas que compõem esta região. Assim como no espaço brasileiro, as lavouras ditas comerciais, voltadas, em sua maioria, para a exportação, têm ganhado espaço substituindo antigos usos.

Na região como um todo, há certo declínio de algumas culturas, haja vista o algodão e o arroz, ao mesmo tempo que há o surgimento de outras culturas na pauta de produção a partir de 2004, como é o caso do sorgo, da soja e do abacaxi, voltados, sobretudo para a exportação. Atualmente, como principais produtos da região, têm-se o melão $(78,10 \%$ de participação no total da produção do Ceará e do Rio Grande do Norte, juntos), a melancia (71,05\%), a goiaba (46,40\%), a banana $(35,20 \%)$, o algodão herbáceo $(31,01 \%)$, o sorgo granífero $(26,87 \%)$ e o mamão $(19,45 \%)$. Todos esses dados foram obtidos a partir do IBGE - Produção Agrícola Municipal.

Trata-se de uma redefinição da pauta produtiva, fruto da nova lógica de modernização agrícola voltada para o agronegócio que promove reflexos no processo de urbanização. Atualmente, a região produtiva agrícola em análise é um dos destaques do Brasil agrícola, onde há um incremento no

Mercator - volume 9, número 20, 2010: set./dez. 
desenvolvimento de áreas urbanas, cuja lógica de organização deve-se às relações cada vez maiores estabelecidas no contexto da globalização da produção e do consumo agropecuário. Por causa do grande número de variáveis que nela passam a interferir, a urbanização dessa região torna-se muito complexa. Entre estas variáveis, incluem-se a modernização agrícola com consequente especialização das produções, o crescimento da produção material e não material, o aumento do trabalho intelectual, entre outras que tornam difícil, por exemplo, considerar as antigas relações campo-cidade.

Esta região produtiva agrícola, associada ao agronegócio de frutas, seria um dos exemplos da dinâmica mencionada, lugar que responde de forma rápida à produção agrícola globalizada, onde surgem novas atividades econômicas, relacionadas em sua maioria ao setor terciário. Segundo Elias (2006d, p.6), "em todas as áreas de expansão do agronegócio globalizado, é visível o crescimento da urbanização e de aglomerados urbanos". Em continuidade, a autora mostra como ocorre o desenvolvimento urbano associado ao consumo produtivo (SANTOS, 1993), observando como acontece a globalização da produção agropecuária moderna, a partir da inserção da ciência e da tecnologia no processo produtivo e distributivo e da intensificação de muitos novos produtos e serviços. É importante destacar que o dinamismo da economia urbana pode ser evidenciado não simplesmente pela expansão dos estabelecimentos comerciais, mas, principalmente, pela movimentação financeira dos setores que o envolvem.

O comércio produtivo de algumas cidades componentes da região de estudo merece distinção. Um bom exemplo, guardada a diferença entre a realidade de cada uma dessas cidades, são Mossoró $(\mathrm{RN})$ e Limoeiro do Norte (CE). Esta última concentra 50\% dos estabelecimentos que atendem à demanda agrícola moderna da região jaguaribana, segundo pesquisa direta realizada por Chaves (2005). De acordo com referida pesquisa, dos 48 estabelecimentos existentes nesta região, 24 estão localizados em Limoeiro do Norte e apresentam grande expressividade no seu alcance regional, ou seja, os estabelecimentos do comércio produtivo agrícola dessa cidade atendem a toda a região do Baixo Jaguaribe, Ceará. Ademais, nos últimos anos, vêm disputando espaço de venda tanto com os representantes de empresas multinacionais que visitam as fazendas agrícolas oferecendo seus produtos quanto com Mossoró, que também atende a toda região produtiva, em particular os produtores da Chapada do Apodi.

Ainda, conforme Elias (2006b), é durante o período de safra das principais culturas de cada área que podemos distinguir com maior clareza as especializações das cidades; é neste período que temos um considerável crescimento do número de empregos agrícolas temporários, obviamente, dependendo do tipo de cultura, pois algumas culturas permanentes, como a banana, embora contratem mais trabalhadores no período de colheita, mantêm seu quadro anual de contratados quase constante, diferentemente do melão, cultura temporária. Prossegue Elias: "O importante é destacar que aumenta exponencialmente o consumo produtivo agrícola, assim como consumptivo, que gera inúmeros fluxos, materiais e de informação, de diferentes complexidades" (p.64).

Um exemplo é o município de Baraúna $(\mathrm{RN})$. Com uma única avenida cruzando a sede municipal, a cidade, que em meia hora de caminhada é conhecida quase por completo, mantém sua tranquilidade na maior parte dos meses do ano. Todavia, "o município de Baraúna de setembro a janeiro fervilha de pessoas".

Obviamente, não é apenas o consumo produtivo que se dinamiza nestas cidades, pois o consumo consumptivo, redefinido nas últimas décadas pela revolução do consumo, também é dinamizado tanto pelo crescimento populacional quanto pela renda da população. Esta não foi necessariamente aumentada nestas cidades, mas passou a ter um diferencial por meio da existência do mercado de trabalho formal em atuação crescente na região.

Com a melhoria do poder aquisitivo das pessoas, o terciário das cidades foi dinamizado, surgiram casas comerciais especializadas até então inexistentes - e um caso particular comum em pequenas cidades onde parte considerável dos seus moradores trabalha em grandes empresas agrícolas e o comércio passa a ser completamente dependente da renda destes trabalhadores. Quixeré, localizada no Baixo Jaguaribe (CE), e mais especificamente um de seus distritos, Lagoinha, é um 
bom exemplo desta lógica, pois muitos dos seus moradores são funcionários da multinacional Del Monte Fresh Produce Ltda. A movimentação do terciário mantém relação direta com a renda provinda dos seus salários.

Tanto no Brasil como na região produtiva em estudo, antes do processo de modernização da agropecuária, o consumo do campo era principalmente consumptivo. Este, segundo Elias (2003), é aquele que cria demandas heterogêneas. Atualmente, o que ocorre nas áreas que se inserem de modo complexo no processo de modernização da agricultura é que o consumo produtivo agrícola acaba por adaptar as cidades mais próximas às suas principais demandas. Na região produtiva em estudo, o consumo produtivo associado à produção agropecuária moderna tem-se dinamizado bastante, criando, inclusive, lojas matrizes e filiais em seus municípios.

O espaço intraurbano das cidades que vem sendo produzido em toda a região de estudo é um reflexo das metamorfoses ocasionadas não apenas no espaço regional nordestino, mas em parte considerável das cidades do Brasil. Entretanto, certas particularidades locais tornam algumas consequências diferenciadas em cada parte. Conflitos nos usos do solo e do espaço intraurbano, problemáticas quanto aos espaços de transição urbano-rural, questões relacionadas à infraestrutura e aos transportes, entre outras, são apenas alguns dos pontos de discussão no tocante ao espaço intraurbano da região produtiva em análise. Tudo passa a ser redefinido em decorrência das transformações sugeridas pela modernização agrícola e pelo agronegócio.

A velocidade das transformações em curso na região pode ser observada pelas metamorfoses tanto das forças produtivas inseridas pelas empresas agrícolas, quanto das relações sociais de produção, com o aumento da exploração direta por parte das grandes empresas agrícolas, nacionais e multinacionais. A partir da reestruturação atual dos sistemas técnicos e das políticas públicas em andamento, estaduais e federais, Elias (2005) acredita que o agronegócio deverá ter, em curto espaço de tempo, ainda mais força de reorganização da economia, do espaço agrário e urbano das regiões submetidas a esta lógica, incluindo o fornecimento da mão de obra braçal e especializada, rebatendo de forma direta no incremento dos outros setores econômicos.

\section{DINÂMICA POPULACIONAL E MERCADO DE TRABALHO}

Além das transformações verificadas na economia urbana da região, o agronegócio da fruticultura potencializa um novo padrão tecnológico de produção irrigada. Concretiza transformações na dinâmica populacional e no mercado de trabalho local mediante intervenção de determinados atores sobre o espaço, como as empresas agrícolas, com fortes reflexos nas formas de organização do trabalho.

Entretanto, para estes atores poderem iniciar sua atuação direta nessa região, muitos outros acontecimentos tiveram de se concretizar. Na realidade, desde a década de 1960 o governo federal tem gerido a adequação da produção e do território pela reprodução ampliada do capital na agropecuária brasileira. No Brasil, as metamorfoses importantes à globalização do setor agropecuário culminaram em transformações substanciais nas relações sociais de produção e na organização dos espaços agrícolas (ELIAS, 2002b).

Os mecanismos de intervenção do Estado no Nordeste remontam ao final do século XIX, com a atuação do IOCS, atual Departamento Nacional de Obras Contra as Secas. A partir da metade do século XX, surgem instituições como a SUDENE mostrando, por meio dos seus estudos, que uma das formas de viabilizar a agricultura sob moldes comerciais no semiárido seria a irrigação. Desse modo, a década de 1970 é marcada pela criação de políticas públicas voltadas para a irrigação. Entre estas políticas, sobressai o Programa de Irrigação do Nordeste, cujo objetivo era justamente aproveitar os vales úmidos e elevar a produtividade desta região. Surgem, assim, os grandes perímetros irrigados públicos que iriam alterar de forma bastante contundente a realidade da mencionada região.

Mas a década de 1980 traz uma mudança nas principais questões de incentivo à irrigação. Destas, uma das mais importantes é o incentivo à irrigação privada, que se segue pela década de 
1990, quando vimos a ampliação do apoio a esse tipo de irrigação, com vistas a incrementar a competitividade para o agronegócio globalizado regida pela iniciativa privada.

Neste período, há a implantação de grandes empresas agrícolas privadas, as quais atuavam em toda a região produtiva agrícola. Em 1985, iniciou-se a consolidação do movimento empresarial no Vale do Açu, caracterizada como um processo de apropriação privada do investimento público. As grandes empresas então instaladas no Vale pareciam já saber que a intervenção estatal seria localizada (SILVA, 1992).

Ainda na década de 1980, a produção agrícola na região produtiva em análise sofreu profundas transformações no sentido do estabelecimento de um nível mais moderno de produção. Essas metamorfoses podem ser observadas na diversificação de culturas (começam a despontar culturas como melão, melancia, abacaxi e outras, em detrimento de culturas tradicionais), na constituição do mercado de trabalho, onde as relações do tipo assalariamento temporário - safristas, agrícolas não-rurais - passam a ter um peso bastante relevante na constituição da força de trabalho do setor agropecuário local, além da tendência de expansão de formas de trabalho tipicamente capitalistas.

Trabalhamos com os dados da RAIS, e eles nos ajudam a refletir melhor como esse processo vem-se dando. Por exemplo, a análise da distribuição do emprego por setores mostra a relevância do emprego na agropecuária da região. Como sabemos, a fruticultura é uma atividade que requer elevado número de mão de obra em virtude do incipiente processo de mecanização exigido pela atividade durante as fases do seu processo produtivo. Salientamos que o recorte temporal adotado neste estudo privilegia as transformações verificadas na região a partir da década de 1980, quando nela se consolida o agronegócio e se estende até períodos mais recentes. Interessou-nos mostrar aspectos das transformações econômicas e territoriais ocorridas na região ao longo de 1980 até início da década de 2000, quando é claro o crescimento absoluto de empregos formais no setor da agropecuária na região em estudo (Tabela 3). No primeiro intervalo relativo aos anos de 1985 a 1995, podemos observar um crescimento percentual da ordem de 429,59\% (no Nordeste como um todo foi de 204,62\%) no número de empregos formais. Esse número não é tão significativo no intervalo de 1995-2004 (52,12\%), mas um aumento considerável pode ser identificado no intervalo de 1985-2004 com um total de 705,62\%, enquanto, de modo geral, no Nordeste foi de apenas $340,80 \%$. Em todos os intervalos, os dados da região de estudo superam o total da região nordeste.

Tabela 1 - Empregos existentes em 31/12 no setor da agropecuária nos estados da região Nordeste

\begin{tabular}{|c|c|c|c|c|c|c|c|c|c|}
\hline UNIDADE & \multicolumn{3}{|c|}{ EMPREGOS EXISTENTES } & \multicolumn{3}{|c|}{ DIFERENÇA ABSOLUTA } & \multicolumn{3}{|c|}{ VARIAÇÃO PERCENTUAL } \\
\hline Municípios & 1985 & 1995 & 2004 & $1985-1995$ & $1985-2004$ & $1995-2004$ & $1985-1995$ & $1985-2004$ & $\begin{array}{l}1995- \\
2004\end{array}$ \\
\hline Alagoas & 6.290 & 14.153 & 9.997 & 7.863 & 3.707 & -4.156 & 125,01 & 58,93 & $-29,36$ \\
\hline Bahia & 11.690 & 48.860 & 79.447 & 37.170 & 67.757 & 30.587 & 317,96 & 579,61 & 62,60 \\
\hline Ceará & 8.379 & 9.958 & 18.827 & 1.579 & 10.448 & 8.869 & 18,84 & 124,69 & 89,06 \\
\hline Maranhão & 2.141 & 6.714 & 10.081 & 4.573 & 7.940 & 3.367 & 213,59 & 370,85 & 50,17 \\
\hline Paraíba & 1.216 & 9.546 & 16.265 & 8.330 & 15.049 & 6.719 & 685,03 & 1237,58 & 70,38 \\
\hline Pernambuco & 16.577 & 48.660 & 57.993 & 32.083 & 41.416 & 9.333 & 193,54 & 249,84 & 19,18 \\
\hline Piauí & 846 & 2.135 & 4.632 & 1.289 & 3.786 & 2.497 & 152,36 & 447,51 & 116,95 \\
\hline $\begin{array}{l}\text { Rio Grande do } \\
\text { Norte }\end{array}$ & 3.219 & 13.081 & 22.960 & 9.862 & 19.741 & 9.879 & 306,37 & 613,26 & 75,52 \\
\hline Sergipe & 1.585 & 5.124 & 8.763 & 3.539 & 7.178 & 3.639 & 223,28 & 452,87 & 71,01 \\
\hline Nordeste & 51.943 & 158.231 & 228.965 & 106.288 & 177.022 & 70.734 & 204,62 & 340,80 & 44,70 \\
\hline Região & 1.990 & 10.539 & 16.032 & 8.549 & 14.042 & 5.493 & 429,59 & 705,62 & 52,12 \\
\hline
\end{tabular}

Fonte: MTE/RAIS (1985-1995-2004) 
Na Tabela 2, consta uma síntese dos números absolutos e da variação dos estabelecimentos e do número de empregados formais nos grandes setores da economia no período de 1985 a 2004. Como mostram os dados, a atividade agropecuária sobressaiu e apresentou crescimento do emprego formal maior do que as outras atividades $(705,62 \%)$. O destaque vai para os municípios de Limoeiro do Norte, Quixeré, Ipanguaçu, Pendências, Baraúna e Mossoró, embora este último sofra um decréscimo de 44,30\% na quantidade de empregados formais na agropecuária entre os anos de 1995 e 2004 (em números absolutos teríamos uma queda de 7.702 para 4.290 empregados), explicável, em parte, pela crise enfrentada pela empresa Maísa. É importante frisar que a ocupação formal na agricultura é um bom indicador para pensarmos na difusão do agronegócio.

Tabela 2 - Número de estabelecimentos e quantidade de empregados na indústria, no comércio, nos serviços e na agropecuária na região produtiva - 1985, 1995, 2004

\begin{tabular}{|c|c|c|c|c|c|c|c|c|}
\hline \multirow{2}{*}{ SETORES } & \multicolumn{4}{|c|}{ ESTABELECIMENTOS } & \multicolumn{4}{|c|}{ EMPREGADOS } \\
\hline & 1985 & 1995 & 2004 & $2004(\%)$ & 1985 & 1995 & 04 & $04(\%)$ \\
\hline Total & 1.362 & 2.331 & 5.239 & 284,65 & 24.898 & 46.978 & 79.015 & 217,35 \\
\hline Indústria & 258 & 444 & 817 & 216,66 & 5.008 & 9.424 & 17.544 & 250,31 \\
\hline Comércio & 640 & 1.190 & 2.695 & 321,09 & 3.896 & 5.120 & 12.417 & 218,71 \\
\hline Serviços & 439 & 587 & 1.341 & 205,46 & 14.004 & 21.895 & 33.022 & 135,80 \\
\hline Agropecuária & 25 & 110 & 386 & 1.444 & 1.990 & 10.539 & 16.032 & 705,62 \\
\hline
\end{tabular}

Fonte: MTE/RAIS. (1985-1995-2004)

Da mesma forma, os municípios onde o emprego formal mais cresceu na agropecuária são também aqueles onde a produção das principais culturas para exportação se destaca, ou seja, onde as principais empresas da região produzem. Limoeiro do Norte é o maior produtor de abacaxi, enquanto Quixeré, Baraúna e Mossoró são os principais produtores de melão, e Ipanguaçu, de banana.

Portanto, o estudo do mercado de trabalho agrícola formal regional colabora para a melhor compreensão da atuação dos elementos de transformação das relações de produção da região produtiva em análise, a partir de especificidades do processo geral da globalização da agricultura, já que a flexibilidade que rege o atual padrão produtivo rebate intensamente na forma de organizar o trabalho.

Paralelamente a uma revolução tecnológica da produção agropecuária e agroindustrial e às transformações nas relações de trabalho, ocorreram transformações demográficas, marcadas por crescimento populacional, particularmente urbano. Ao analisarmos os dados por município, percebemos que a maioria apresenta taxas de crescimento da população urbana. Apenas Carnaubais teve redução, mas isso se deve ao desmembramento do distrito de Porto do Mangue.

Ainda do ponto de vista demográfico, é importante destacar que a população regional registrou expressivos índices de expansão populacional durante a segunda metade do século XX, com taxa de crescimento de 40\% (saltando de 489.975 habitantes para 686.409), no período de 1980 a 2000. Em alguns municípios, verifica-se ritmo de crescimento demográfico acima desse percentual.

Sobressaem os seguintes: Russas - CE (74,79\% - de 38.513 para 57.320 habitantes), Limoeiro do Norte - CE (51,49\% - de 32.754 para 49.620 habitantes), Mossoró - RN (46,48\% - de 145.981

Mercator - volume 9, número 20, 2010: set./dez. 
para 213.841 habitantes) e Açu - RN (39,26\% - de 34.398 para 47.904 habitantes). No entanto, São João do Jaguaribe - CE (3,77\% - de 8.335 para 8.650 habitantes), Palhano - CE (14,93 \% - de 7.105 para 8.166 habitantes), Grossos - RN (4,49\% - de 7.894 para 8.249 habitantes) e São Rafael - RN $(14,09 \%$ - de 7.188 para 8.201$)$ tiveram taxa média de crescimento populacional bem abaixo do total da região. Curiosamente estes são municípios onde a fruticultura não se instalou. Por exemplo, Carnaubais sofreu um decréscimo populacional de 32,48\%. Ademais, enquanto a população urbana regional cresceu $85,46 \%$ (saltou de 260.059 habitantes para 482.316), a população rural teve um declínio de 11,23 \%, ou seja, foi de 229.916 para 204.093 habitantes. (Censo Demográfico - IBGE)

É visível a diferença entre as taxas de crescimento da população urbana sobre a rural, sobretudo em municípios da região como Jaguaruana, Morada Nova, Palhano e Quixeré, no Ceará, e Mossoró, São Rafael e Serra do Mel, no Rio Grande Norte. Tais municípios são exatamente aqueles onde a população rural mais diminuiu e paralelamente a população urbana mais cresceu. É interessante mencionar o seguinte: os municípios de Limoeiro do Norte (de 19.183 para 21.407 habitantes) e Russas (de 19.955 para 21.997 habitantes) foram os únicos a apresentar um acréscimo (embora bem pequeno) da sua população rural. Provavelmente isso decorreu da implantação dos perímetros irrigados na região do Baixo Jaguaribe - CE.

A taxa de urbanização dos municípios da região pode ser verificada na sequência. Alguns dos municípios apresentaram urbanização mais significativa para a década de 2000. Entre eles, Serra do Mel (99,58\%), Mossoró (93,09\%), Tibau (84,07\%), Itajá (82,06\%), Areia Branca (79,27\%), Pendências (78,44\%), Grossos (76,06\%), Açu (72,32\%), Alto do Rodrigues (68\%), São Rafael (65\%), Baraúna (63,23\%), no Rio Grande do Norte, e Limoeiro do Norte $(63,05 \%)$ e Russas $(60,33 \%)$, no Ceará. Entretanto, esses crescimentos percentuais têm de ser pensados de acordo com a realidade da região, pois estes mesmos valores para uma grande metrópole, por exemplo, representariam algo muito diferente. Outra observação importante é que alguns municípios têm suas taxas de urbanização elevadas por motivos bem singulares.

Tais taxas devem, pois, ser analisadas com algumas ressalvas. Este é o caso de Serra do Mel, no Rio Grande do Norte, cuja origem remonta aos assentamentos de reforma agrária onde os assentados vivem em núcleos considerados pelo Instituto Brasileiro de Geografia e Estatística como áreas urbanas. Até o ano de 1995 este município ainda não possuía sequer uma sede.

Em 1980, dos 25 municípios componentes da região em estudo, em apenas três, a população urbana era superior à rural: Açu, Areia Branca e Mossoró, todos no Rio Grande do Norte. Em 2000, esse número aumentou para 19 municípios. Destes, os mais urbanizados são Limoeiro do Norte, Russas e Tabuleiro do Norte, no Ceará, e Açu, Alto do Rodrigues, Itajá, Jucurutu, Pendências, Porto do Mangue, Areia Branca, Baraúna, Tibau, Mossoró, Serra do Mel e Grossos, no Rio Grande do Norte.

A modernização da agricultura e a substituição da pauta produtiva de algumas culturas pelas frutas para exportação estabeleceram tanto um considerável processo de urbanização como um elevado crescimento econômico para a região produtiva em análise, com transformações inclusive dos elementos sociais da sua estrutura agrária. Assim, o processo de concentração fundiária agrava-se dia a dia, com grande parte das terras agricultáveis passando para propriedade de empresas agrícolas. 
Tabela 3 - Taxa de urbanização por município - 1980, 1991, 2000

\begin{tabular}{|c|c|c|c|}
\hline UNIDADE ESPACIAL & 1980 & 1991 & 2000 \\
\hline Brasil & 67,58 & 75,59 & 81,24 \\
\hline Rio Grande do Norte & 58,73 & 69,1 & 73,34 \\
\hline Ceará & 53,14 & 65,37 & 71,53 \\
\hline Região de estudo & 53,07 & 64,82 & 70,26 \\
\hline \multicolumn{4}{|c|}{ Municípios e microrregiões } \\
\hline Alto Santo & 23,05 & 28,78 & 28,79 \\
\hline Ibicuitinga & $*$ & 28,22 & 46,49 \\
\hline Jaguaruana & 33,15 & 45,27 & 47,74 \\
\hline Limoeiro do Norte & 41,32 & 55,98 & 63,05 \\
\hline Morada Nova & 29,59 & 44,98 & 51,26 \\
\hline Palhano & 28,26 & 44,36 & 55,81 \\
\hline Quixeré & 23,34 & 48,49 & 56,66 \\
\hline Russas & 48,15 & 58,1 & 60,63 \\
\hline São João do Jaguaribe & 22,08 & 31,42 & 34,34 \\
\hline Tabuleiro do Norte & 38,08 & 50,53 & 54,77 \\
\hline Baixo Jaguaribe & 34,76 & 48,12 & 54,6 \\
\hline Açu & 59,61 & 67,67 & 72,32 \\
\hline Alto do Rodrigues & 42,87 & 64,54 & 68,23 \\
\hline Carnaubais & 20,32 & 36,59 & 25,68 \\
\hline Ipanguaçu & 18,77 & 23,76 & 36,49 \\
\hline Itajá & $*$ & $*$ & 82,06 \\
\hline Jucurutu & 30,27 & 50,23 & $\overline{59,98}$ \\
\hline Pendências & 65,05 & 75,67 & 78,44 \\
\hline Porto do Mangue & $*$ & $*$ & 56,22 \\
\hline São Rafael & 41,41 & 57,97 & 65,65 \\
\hline Vale do Açu & 43,27 & 56,07 & 63,89 \\
\hline Areia Branca & 75,05 & 80,14 & 79,27 \\
\hline Baraúna & - & 56,69 & 63,23 \\
\hline Grossos & 67,41 & 74,11 & 76,06 \\
\hline Mossoró & 84,21 & 92,23 & 93,09 \\
\hline Serra do Mel & $*$ & 15,38 & 99,58 \\
\hline Tibau & $*$ & $*$ & 84,07 \\
\hline Mossoró & 82,51 & 85,77 & 89,48 \\
\hline
\end{tabular}

Fonte: Censos Demográficos do IBGE. ( 1980-1991-2000)

\section{CONSIDERAÇÕES FINAIS}

Um de nossos principais desafios neste trabalho foi pensar a região produtiva agrícola, isto é, sua consolidação e desenvolvimento. Concluímos que ela se estabelece entre os estados do Rio Grande do Norte e do Ceará, onde os limites político-administrativos pouco têm servido de obstáculo para que os principais agentes econômicos hegemônicos a percebam como uma única região. Esta, aqui chamada de região produtiva agrícola, a qual se estabelece obedecendo à lógica das grandes holdings que controlam o agronegócio da fruticultura, é dominada por uma coesão funcional do agronegócio.

Para pensarmos na consolidação da região produtiva agrícola, foi fundamental analisar sua integração com o mercado nacional e sua articulação com a economia mundial promovidas por empresas agrícolas. Essa articulação é impulsionada, principalmente, pela chegada nesta região de empresas multinacionais. É exatamente a organização destas empresas que nos ajuda a compreen- 
der a dinâmica e a organização da região produtiva agrícola em análise, pois muitas atividades (de produção, financeiras, administrativas etc.) são desenvolvidas em municípios diferentes, ou seja, algumas empresas produzem no Ceará e têm seus escritórios no Rio Grande do Norte. Ademais, a produção é realizada pelas empresas sem que estas se preocupem com a divisão político-administrativa dos estados.

Importante perceber que esta região, embora seja um ponto luminoso, não é homogênea. Isto é, mesmo na referida região, notamos que alguns municípios são mais maleáveis à expansão de um meio técnico-científico-informacional, caracterizado pela presença de "objetos técnicos", "fixos artificiais" associados, principalmente, às infraestruturas econômicas.

A produção agrícola voltada para a exportação se dinamizou bastante, sobretudo com o incremento da fruticultura, e, apesar de boa parte dos municípios apresentarem certa alteração nos tipos de culturas produzidas, sinalizando um novo momento para sua lógica agrícola e econômica, determinados municípios sobressaíram na produção das principais culturas exportadas, como Limoeiro do Norte, Quixeré, Baraúna e Mossoró, conforme já foi mencionado.

No que se refere à economia urbana da região, especificamente ao comércio produtivo de algumas cidades componentes da região de estudo, merecem destaque, guardada a diferença entre a realidade de cada uma dessas cidades, Mossoró (RN) e Limoeiro do Norte (CE). O agronegócio da fruticultura, na região, não somente tem mobilizado o comércio e os serviços, mas também propiciado a algumas cidades se transformar em "locus" da produção agropecuária, onde centros de pesquisa são criados, a infraestrutura dos transportes é redefinida, surgem as consultorias etc. Nesse sentido, algumas cidades na região se destacam, como é o caso de Limoeiro do Norte (CE), Mossoró (RN) e Açu (RN).

Os municípios de destaque estão tanto no Ceará quanto no Rio Grande do Norte, e as fortes relações estabelecidas entre estes municípios, política e administrativamente separados, nos fazem retornar aos estudos de Valverde (1961, p. 483), quando este afirma que "é sempre útil comparar os baixos vales do Açu e do Jaguaribe, já que as condições naturais são semelhantes, assim como as atividades econômicas, o habitat e a elevada densidade de população", apontando certa relação ocasionada pela semelhança entre essas regiões. Entretanto, na realidade, além de uma comparação, é necessário apreender as novas relações estabelecidas entre estes espaços, que os tornam cada vez mais próximos, não simplesmente pela sua proximidade geográfica em termos de localização, mas, em particular, por seus aspectos sociais e econômicos.

Entre a região jaguaribana e a potiguar, em especial entre as cidades de Limoeiro do Norte (CE), Açu (RN) e Mossoró (RN), intensificam-se as trocas e as relações de todas as naturezas. Há um fluxo de funcionários especializados a se realizar diariamente de uma cidade para outra, por exemplo.

Como a expansão dos sistemas de objetos e dos sistemas de ação (Santos, 2004) é fundamental para dotar o território de fluidez para os investimentos produtivos, devemos mencionar o importante papel do Estado, direta ou indiretamente, para a produção do espaço, seja por meio das políticas públicas ligadas ao setor, seja pela implantação desses sistemas de objetos.

Esta região tem-se organizado para atender às necessidades do mercado, mais especificamente de grandes empresas agrícolas, onde o crescimento econômico se sobrepõe ao desenvolvimento socioespacial, favorecendo o empobrecimento de grandes parcelas populacionais, criando cidades sem cidadãos e ampliando cada vez mais a segregação social. Esta urbanização ocorre em todos os municípios da região, tanto na cidade quanto no campo, gerando também o que podemos chamar de "outro lado da urbanização", ou seja, a pobreza. Um bom exemplo dessa realidade, particularmente no campo, é o estabelecimento de condições de miséria quase absoluta. Limoeiro do Norte, Quixeré, Mossoró expressam claramente este processo.

Indiscutivelmente a modernização desta região tem ocorrido de forma incompleta. Esta é a ponta de lança para um processo de urbanização bastante complicado que reproduz um modelo urbano extremamente caótico com todos os problemas urbanos conhecidos. Com o acelerado cres- 
cimento urbano e com o aumento populacional, problemas das mais diversas naturezas surgem nas cidades que compõem a região. Falta de moradia, de saneamento básico, de empregos, escassez de hospitais, de escolas, de transportes públicos, são apenas algumas das mazelas às quais estão sujeitas essas cidades, o que denota imensa crise urbana. Grave também tem sido a degradação ambiental da região. Os solos e os recursos hídricos são os mais afetados e, consequentemente, a população e os trabalhadores agrícolas, em especial, constituem o principal alvo dessa dinâmica.

Como afirma Elias (2006b), a reprodução das desigualdades socioespaciais que regem a inserção dos lugares de reserva do espaço agrário nordestino torna as novas regiões produtivas em meras regiões do fazer e não em regiões do reger, pois suas populações não conseguem exercer nenhuma ingerência sobre os processos nelas ocorridos.

Desse modo, finalmente, nossas reflexões nos levam a afirmar o seguinte: a região produtiva agrícola analisada é um dos exemplos de que o atual sistema econômico promove tanto grande riqueza quanto visível pobreza. A modernização agropecuária não se completou. Pior ainda: agravou questões como a especulação fundiária e a imobiliária, a favelização urbana e rural, o acirramento da crise urbana e dos problemas ambientais, dentre tantos outros sentidos de forma mais intensa pela população mais pobre. Merece estudos mais aprofundados cada um destes pontos.

\section{REFERÊNCIA BIBLIOGRÁFICA}

CARVALHO, O. de. Sustentação da agricultura irrigada no Nordeste. In: CONGRESSO BRASILEIRO DE ECONOMIA E SOCIOLOGIA RURAL, Anais. Natal, 1997. (Disponível em CD-ROM).

CHAVES, Maria Lucenir Jerônimo. Urbanização e modernização da agricultura em Limoeiro do Norte (CE): impactos socioespaciais. (Dissertação) Mestrado em Geografia, Universidade Estadual do Ceará, Fortaleza, 2005.

ELIAS, D. Integração competitiva do semiárido. In: ELIAS, D.; SAMPAIO, J. L. F. (org.). Modernização excludente. Fortaleza: Edições Demócrito Rocha. 2002a. p.11-36. (Coleção Paradigmas da Agricultura Cearense).

ELIAS, D. Modernização da produção agropecuária. In: ELIAS, D. (org.). O novo espaço da produção globalizada. Fortaleza: Edições Demócrito Rocha. 2002b.

ELIAS, D. Globalização e agricultura. A Região de Ribeirão Preto - SP. São Paulo: Editora da Universidade de São Paulo, 2003.

ELIAS, D. Reestruturação produtiva da agricultura cearense: rumo à desintegração competitiva e à fragmentação do espaço agrário. In: SILVA, José Borzacchiello da; CAVALCANTE, Tércia Correia; DANTAS, Eustógio Wanderley Correia; SOUSA, Maria Salete de et al. Ceará: um novo olhar geográfico. Fortaleza: Edições Demócrito Rocha, 2005.

ELIAS, D. Ensaios sobre os espaços agrícolas de exclusão. Revista Nera, n.8, 2006a.

ELIAS, D. Agronegócio e desigualdades socioespaciais. In: ELIAS, D.; PEQUENO, R. (org.). Difusão do agronegócio e novas dinâmicas socioespaciais. Fortaleza: BNB. 2006b.

ELIAS, D. Globalização e fragmentação do espaço agrícola do Brasil.Revista Electrônica de Geografía Y Ciencias Sociales. Universidad Barcelona. Vol. X, n. 218 (03), 2006c. ISSN: 1138-9788.

ELIAS, D. Fronteiras em mutação no Brasil agrícola. In: Simpósio da Associação Nacional de Pós-Graduação e Pesquisa em Planejamento Urbano e Regional - ANPUR, durante a 58 Reunião Anual da Sociedade Brasileira para o Progresso da Ciência - SBPC. Anais. Florianópolis: ANPUR/UFSC, 2006d.

GRAZIANO DA SILVA, J. F. A nova dinâmica da agricultura brasileira. 2. ed. Campinas, SP: Unicamp/ IE,1998.

SANTOS, M. O espaço dividido. Rio de Janeiro: Francisco Alves, 1979.

SANTOS, M. Espaço e método. São Paulo: Nobel, 1985.

SANTOS, M. Metamorfoses do espaço habitado. São Paulo: Hucitec, 1988. 124 p.

SANTOS, M. Urbanização brasileira. São Paulo: Hucitec, 1993. 173 p.

Mercator - volume 9, número 20, 2010: set./dez. 
SANTOS, M. Por uma economia política da cidade. São Paulo: Hucitec, 1994.

SANTOS, M. Por uma outra globalização. Rio de Janeiro: Record, 2000.

SANTOS, M. A natureza do espaço: técnica e tempo: razão e emoção. 4. ed. São Paulo: Editora da Universidade de São Paulo, 2004.

SILVA, A. G. da. A parceria na agricultura irrigada do Baixo Açu. Natal: UFRN/CCHLA, 1992. (Coleção Humanas Letras, n.6).

SILVA, A. G. da. Trabalho e tecnologia na produção de frutas irrigadas no Rio Grande do Norte. In: CAVALCANTI, J. S. B. (org.). Globalização, trabalho, meio ambiente; mudanças socioeconômicas em regiões frutícolas para exportação. v.1, Recife: 1999. p.307-340

SOJA, E. W. Geografias pós-modernas: a reafirmação do espaço na teoria social. Tradução [da $2^{\mathrm{a}}$ ed. inglesa], Vera Ribeiro; revisão técnica, Bertha Becker; Lia Machado. Rio de Janeiro: Jorge Zahar Ed., 1993.

SOUZA, M. J. N. de.; OLIVEIRA, V. P. V. de.; GRANJEIRO; C. M. M.; Análise geoambiental. In: ELIAS, D. (org.). O novo espaço da produção globalizada. Fortaleza: Edições Demócrito Rocha. 2003.

VALVERDE, O.; MESQUITA, M. G. C. Geografia agrária do Baixo Açu. Revista Brasileira de Geografia. Ano XXIII. n. 3. p. 455 - 492, jul./set. 1961.

Trabalho enviado em setembro de 2010 Trabalho aceito em dezembro de 2010 